\title{
Genetically modified crops and climate change linkages: An Indian perspective
}

\author{
Amanpreet Kaur ${ }^{1}$, Ravinder Kumar Kohli ${ }^{2 *}$, Paramjit Singh Jaswal ${ }^{3}$ \\ ${ }^{1}$ Department of Environment, Post Graduate Government College-46, Chandigarh, India \\ ${ }^{2}$ DAV University, Jalandhar, India \\ ${ }^{3}$ RGNUL, Patiala, Punjab, India; \\ *Corresponding Author: rkkohli45@yahoo.com, rkkohli45@gmail.com, aman_envirocare@yahoo.com
}

Received 29 June 2013; revised 29 July 2013; accepted 19 August 2013

Copyright (c) 2013 Amanpreet Kaur et al. This is an open access article distributed under the Creative Commons Attribution License, which permits unrestricted use, distribution, and reproduction in any medium, provided the original work is properly cited.

\begin{abstract}
Genetically Modified Crops (GMCs) and Climate Change (CC) are the two most contentious ecological issues the world faces today. Application of transgenics in agriculture is most debated because of its direct and indirect implications. The advertized benefits in the backdrop of the potentially harmful effects on health and environment make this an issue of greater concern. On the other hand, Climate Change is a problem of enormous scale and its after-effects even more grave. The impact of climate change on agriculture, though well researched, is still very uncertain. Further, the introduction and global embrace of a technology with unverified credentials may prove to be an ill-conceived and ill-timed act. The future of GMC technology in India will be both challenging as well as exciting. Therefore any decision on this front should be taken with scientific rigor and logic. Our aim is to explore this complex inter-relationship and provide impetus for further research.
\end{abstract}

Keywords: Genetically Modified Crops; Climate Change; Carbon Emissions; Agriculture; Bt Crops

\section{INTRODUCTION}

Climate Change (CC) is the greatest challenge mankind faces today. Its impacts like rising sea levels, melting of glaciers, droughts, floods, loss of biodiversity, spread of diseases, continue to increase at rates far steeper than the rate of social change [1]. Scientists, climatologists and governments world-over are striving to find ways to combat this phenomenon. Among its most worrying aspects is the effect on agriculture.
Potential impacts of CC estimated under $\mathrm{HadCM}_{3}$ global climate model of IPCC (Inter-Government Panel for Climate Change) indicate net loss in crop yields by 9 to $22 \%$, even after including beneficial effects of increased $\mathrm{CO}_{2}$ levels and various farm level adaptations [2].

Predictions of changes in crop yield seem difficult, since global CC is bound to alter the cropping pattern in time and spatial scale. To combat this issue, man is manipulating the genetic traits by inserting/altering desired genes into the crops to produce Genetically Modified Crops (GMCs) as per suitability.

Since the first commercial cultivation of transgenic Tomato in 1996, nearly 170 million hectares (mha) of global land is under GMCs cultivation, with USA, Brazil and Argentina as the top three countries (Figure 1(a)). Soya, Maize, Cotton and Canola (Figure 1(b)) are the top four crops [3]. Herbicide tolerance and insect resistance, the two most widely transgenically induced traits (Figure 1(c)), are expected to decrease pesticide usage and increase crop yields.

In India, $\mathrm{Bt}$ cotton is the only GMC being grown commercially. Released for commercial cultivation in March 2002, today it covers 9.4 mha of the total 10.3 mha land under cotton [4]. Despite the wide acceptance, it remains shrouded in controversy and has received a mixed response from the Indian farmers. In the overall context of the extensive and rich background of farming in India, Bt cotton remains a minor change. It is perhaps too early to critically evaluate the impact of such a change. The direct and indirect impacts of these crops on human health, ecology and environment remain to be evaluated and hence, GMCs today still stand at the crossroads of acceptance.

\section{DISSECTING LINKAGES}

In the present scenario of changing climate, huge skepticism surrounds the ability of our agricultural system to 


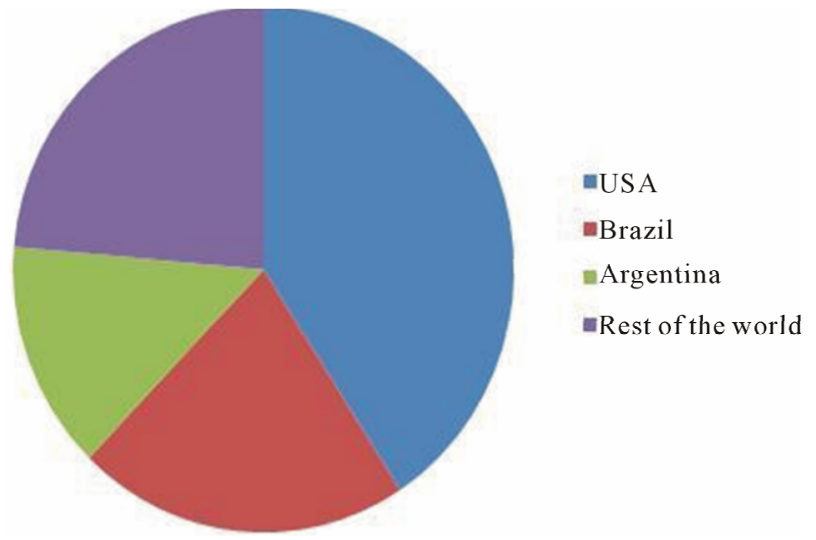

(a)

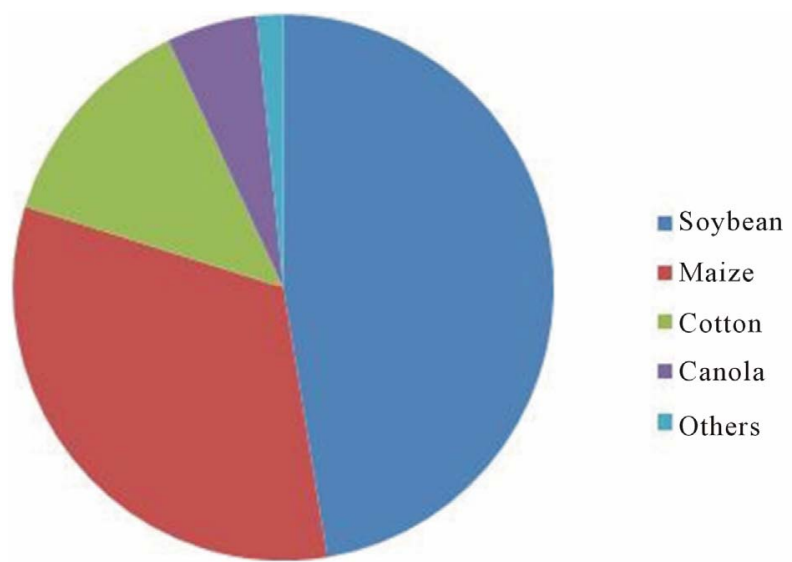

(b)

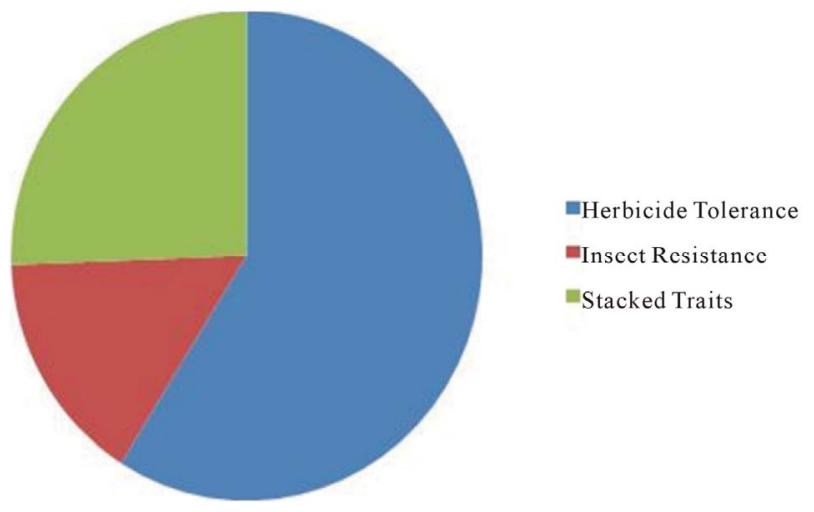

(c)

Figure 1. (a) Country wise Distribution of GMCs Source: Clive 2012; (b) Crop wise world distribution of GMCs Source: Clive 2012; (c) Trait wise distribution of GMCs, Herbicide Tolerance the most popularly grown Source: Clive 2012.

feed the world. High degree of uncertainty imputed to CC and its interactions with agriculture cast doubts on the safety of GMCs. Moreover, agriculture in India is the backbone of the economy. It covers $60.5 \%$ of land area, accounts for $15.7 \%$ of the country's gross domestic product (GDP) and provides employment to 55\% of the work force [5]. Tampering with it, in backdrop of potential CC impacts and carbon emission liabilities, could be disastrous for the country. In the light of given problem, Biotech companies now herald GMCs as solution to CC for feeding our ever growing population in the warmer world.

Interaction between climatic factors and crops is very strong but replacing the conventional crops with GMCs in a warming world gives a new perspective. Intensive crop farming requires large inputs of oil, fertilizers, pesticides which collectively are major contributors to climate change. GMCs also appear to be going on the same lines [6].

Most of the pretensions about these crops as a solution to CC appear to be overdrawn and entirely premature. Successful crop plants are the resultant of interaction between genes and environment (product of dose and period of exposure). Introducing or changing gene(s) is thus no guarantee of success. A multifaceted approach broadens the horizon as GMCs are believed to mitigate green house gas (GHG) emissions in number of ways.

\subsection{Reduced Pesticide Usage with Increased Yield}

Herbicide Tolerant (HT) and Insect Resistant (IR) crops claiming to reduce pesticide usage can further reduce the carbon footprint of the whole process. Low pesticide use means less manufacture, storage, transport and spraying, which collectively brings down the carbon emissions of the process [7]. Increased yields with lesser pesticide use on the same piece of land, reduces the pressure on the system [8]. Increasing the crop yield or reducing the pest attack, in short, converts into profit for its grower as he can grow more on the same piece of land. This is the main objective behind GMC cultivation. Whether it has really been achieved, is still questionable.

It is reported that only in areas where there are frequent disease outbreaks, especially during planting season, the HT and IR crops show better performance. Otherwise, under normal conditions they show little or no impact on crop yields [6]. Compared to conventional cropping/organic systems, GMCs are not expected to show similar results especially in terms of yield and quality. On the other hand, pesticide usage is hardly any different when compared between HT crops and their conventional counterparts. Instead, cultivation of GMCs has led to increased pesticide usage because of the convenience factor.

An even worse scenario which has been widely reported is the development of resistant weeds/super-weeds and secondary pests [9]. Widespread infestation of the exotic mealy-bug species, Phenacoccus solenopsis, was reported on Bt cotton in 2007 in India [10]. Further, the Bollworms have already started showing signs of field evolved resistance to Bt cotton [11]. 


\section{New enemies of GMC fields}

Super-weeds-Gene flow from transgenic crops to its wild relatives could unintentionally confer such benefits to these weedy relatives resulting in the evolution of super-weeds. Such weedy relatives are mostly species related to the crop and so become very difficult to control.

Secondary Pests-A species which was not a pest before but its population increases to densities that cause damage to the crop is called as a secondary pest. Development of secondary pests has recently increased in GMC fields where pesticide applications kill natural enemies of such species and disturbs the biological control [12].

Source-Powles 2008

\subsection{Increased Carbon Retention}

Since man started agriculture, plowing has been a process of aerating the soil, to integrate organic matter and release large amount of carbon gases trapped. However, GMCs are considered as no-till crops which in turn decrease the carbon lost during tillage. In this way, these crops can increase retention of carbon and further bring down the emissions.

But conservation tillage was discovered and practiced even before GMCs came in. It has been practiced as traditional farming technique in India for decades. Thus, reduction in carbon loss by this process is expected to be minimal.

\subsection{Climate-Ready Crops}

Apart from these indirect benefits, some GMCs are being climate proofed to bear the environmental stress in changing climate such as droughts and floods. In some cases, both direct and indirect benefits can also be looked upon from GMCs like the bioengineered nitrogen fixing crops which are expected to increase the nitrogen use efficiency as well as reduce our dependence on fossil fuel based nitrogen fertilizers. It also helps to reduce GHG emissions and water pollution due to leaked nitrogen products.

But there has been very little progress in terms of developing GM nitrogen-fixing and drought resistant crops. Such modification requires major changes in plant metabolism. Its interactions with the agro-ecosystem are unknown. It is a known fact that no seed can germinate in complete absence of moisture. Thus development of a drought resistant crop appears to be relatively impractical.
A safer option would probably be to use the wild relatives of crops growing in the geographically diverse regions of India and develop climate resistant hybrids.

\subsection{Biofuels}

World over, GMCs are being grown for agro-fuel production with $70 \%$ of total GM Soya grown for this purpose only. Bio-fuels are believed to be a cleaner fuel with lower emissions and a befitting alternative to fossil fuels. However, this role of GMCs for increased agro-fuel production replacing fossil fuels is based on very little evidence. Instead, rapid expansion of agro-fuel cultivation can lead to loss of land primarily used for food production, increased chemical usage, displacement of farmers and indigenous people and loss of biodiversity [13].

\subsection{Genetically Engineered Trees}

Genetically engineered trees are also being developed for a range of uses. In China, Poplar species have been genetically engineered, cloned and planted on commercial scale to prevent soil erosion [14]. These fast growing trees fix more $\mathrm{CO}_{2}$ and produce more cellulose for industrial use than conventional trees and appear as a very attractive option. Regarding genetically engineered trees, meaningful and adequate benefits are currently uncertain, keeping in view the complexity of their large habitats and numerous interactions.

\section{DATA MISREPRESENTATION}

Biotech companies often combine several GM traits together in a crop and refer them as stacked GM traits. For example, Monsanto and Dow have developed a maize variety called Smart-Stax containing two herbicide tolerance and six insect resistance traits. International Service for the Acquisition of Agri-Biotech Applications (ISAAA), a non profit organization primarily funded by biotech MNCs, publishes an annual report on GMC status of the world. While calculating the area under GMC, it calculates the area under different GM traits individually and by doing this it multiplies the area under stacked GMCs with the number of GM traits it contains. Thus for the crop with two stacked traits, it claims double the area or in the case of Smart-Stax where it is eight times the area [15]. By such counting, a highly exaggerated and misguiding picture is presented to the world.

Source-FOE 2010 
Whether GMCs can be helpful in reducing carbon emissions or not, is still questionable. These possibilities need to be studied and researched extensively to prove their relevance. Despite claims and counter claims on the pretension of GMCs as solution to climate change, a large number of biotech companies around the world are patenting climate ready genes in a rush. At the recently held United Nation Convention on Biodiversity (CBD) in Nagoya, Japan (18 - 29 October 2010), it was claimed that under the pretext of developing climate ready crops, these biotech companies seek to control worlds' plant biomass. Over 262 patent families, subsuming 1663 patent documents published worldwide (both applications and issued patents) make specific claims on environmental stress tolerance in plants (such as drought, heat, flood, cold, salt tolerance). Out of these over two-thirds are held by three major biotech companies where as public sector researchers hold only $10 \%$ [16].

\section{DICHOTOMOUS GLOBAL DIVIDE}

The acceptance of GMCs is sharply divided over the continents. While, Americans are growing nearly $80 \%$ of total GMCs, Europeans have taken a stringent stand against these crops. Similarly the developing world too is confused over adopting GMCs in a hurry. Geographically, Southern hemisphere, which is expected to suffer more due to climate change, grows negligible GMCs (Figure 2).

If GMCs can actually mitigate climate change impacts, then why they are not being grown in regions of the

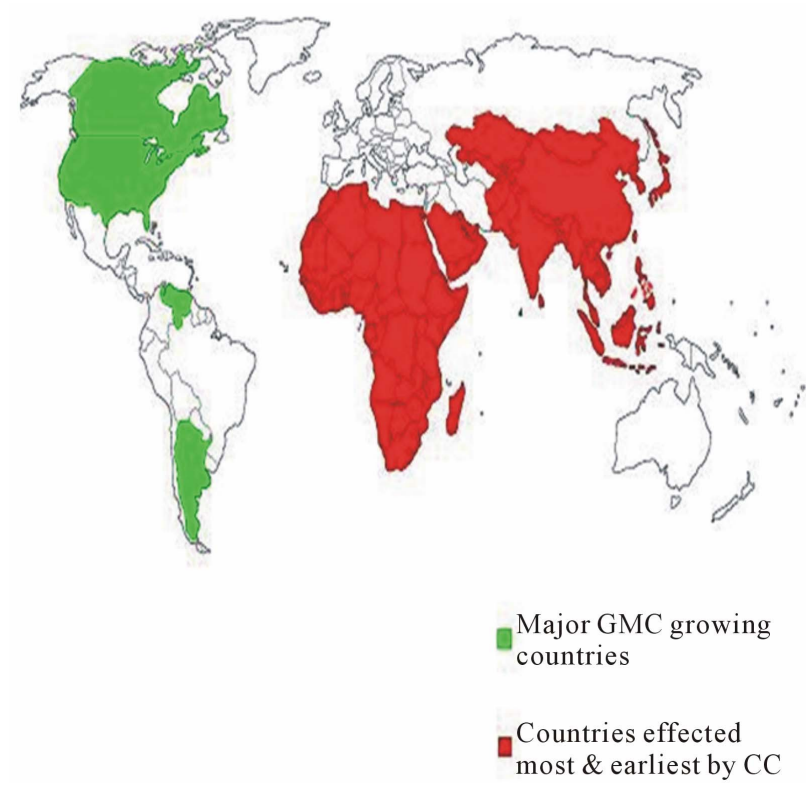

Figure 2. Complete mismatch between countries growing GMCs and the ones' mosteffected by climate change, in wake of claims of GMCs mitigating climate change impacts. world which will suffer earlier and more severely by it? GMC is monoculture based, more suited to large land holders. However in India, where, $80 \%$ of farmers have marginal and small land holdings of less than 2 ha, GMC may not augur well. As they grow a variety of crops together and cannot afford to leave large isolation distances as a pre-requisite in GMC cultivation. Performance of GMCs varies with region, cultural practices, agroclimatic conditions and geographical conditions. In India, Bt Cotton failed miserably in South but fared better in Punjab in North [10].

Lack of legal capacity to monitor, assess and control activities involving GMCs further decreases their chances in developing world. Thus GMCs are not an asset to us, unless they are developed keeping in mind geographic concerns, needs, farming practices, economic background, local innovations and ecology on a whole. This can be best done by involving the local groups, government research agencies, farmers and allowing them to innovate and evolve need based GMCs. But patenting of GMCs by the biotech companies hampers such efforts. Independent research by government agencies becomes difficult because of huge investment involved and lack of information and technological exchange.

Further it is very expensive and difficult to prove the safety of GMCs in the light of various claims of biotech giant which some NGOs and scientists term as misguiding and misleading [17]. Some of the adverse effects attributed to GMCs include new allergens in food supply, antibiotic resistance, production of new toxins, concentration of toxic metals, enhancement of the environment for toxic fungi to grow, increased cancer risks, degradation of the nutritional food value, and other unknown risks that may arise later [18].

An initial study which raised major concern amongst scientific community showed that on consumption of GM soybeans containing brazil-nut gene could induce potentially fatal allergies in people allergic to brazil nut [19]. GM potatoes, that contained Galanthus nivalis agglutinin, caused ripples in the scientific community and biotech companies alike. These potatoes were found to damage vital organs, immune system and stomach lining of rats and affect other non target species [20].

Bt cotton growers from Bathinda (Punjab), India, complained of a chronic skin allergy among the field workers and have to take antihistamines. Increased incidents of dead cattle and sheep grazing on harvested Bt cotton fields in Warangal district (Andhra Pradesh) in Southern India as well as other parts of the country has been reported since 2005 [21]. Such repeated patterns of illness, corroborating evidence, and health reactions have consistently increased and superimposed the known potential risks of GMCs [22]. 


\section{BtBrinjal-A controversy in India that Refuses to Die!}

BtBrinjal, India's first GM Food crop got intertwined in controversies right from the beginning. Following its approval by Genetic Engineering Approval Committee, a safety debate broke out in the country. Union Minister of Environment, Jairam Ramesh took the issue in public domain where it was strongly opposed by various sections of the society. Consequently, a moratorium was put on its release on Feb 9, 2010 and in his decision, the minister appointed six premier academies to scrutinize safety of BtBrinjal and give a rigorous scientific opinion on GMCs. This Inter Academy report on GMCs when released declaredBtBrinjal safe. The very next day, Coalition for GM free India, highlighted malice in the above report terming it as superficial overview without any critical analysis. The BtBrinjal section of the report is accused to have been copied from a pro-GM newsletter of Dept of Biotechnology. Poorly researched, containing plagiarized sections, it had reflected badly on the science academies and was consequently withdrawn [23]. Later an updated report released was tidied up by adding references and details of the only meeting held on June 1, 2010 to discuss this crucial issue. Updated report was termed as scientifically invalid and socially sterile than the original one, by P.M. Bhargava, expert nominated to the Genetic Engineering Approval Committee. Amount of discontent and doubt in minds of common man has reached to limits from where winning the trust will now be even more difficult.

Source: Jayaraman 2010

Considering the economic front, it is generally recognized that GMCs can go a long way in boosting the economy of agriculturally rich countries [24]. Bt Cotton has contributed to the observed leap in cotton productivity, turning India into major cotton exporter [25]. Comparing such obvious economic benefits with intangible ecological losses predicted due to mass GMC cultivation is arduous. There are two contrasting approaches to it. One weighs short term economic gains ignoring the basic law of nature and its ecological impacts. On the contrary, other accounts for long term ecological losses over short term economic gains due to perpetuating loss of biodiversity, development of super-weeds, secondary pests and disturbing the food web oscillations. Long term ecological research only, can settle this economic issue.

GMC and CC have ethical issues also, as success of any new technology depends on its acceptance by the so- ciety. Any scientifically feasible process may not be ethically right. These values are of great prominence in India where people of different religious beliefs live and jointly worship various plants and animals.

India, a major center of biodiversity and is more susceptible to genetic pollution in the wake of increased cultivation of GMCs. The trans-boundary movement, transit, handling and use of all GMCs may have adverse effects on the conservation and sustainable use of biological diversity. Taking into account its possible impact on human health and the environment, it is restricted under the Cartagena Protocol on Biosafety to CBD. The protocol lays down provisions for direct use as feed or food or processing of GMOs, where information of centers of origin and centers of genetic diversity of the recipient or parental organisms is mandatory [26]. Interestingly, the top three GMCs growing countries have not ratified to this protocol (Table 1).

Even if all above mentioned issues are ignored and a developing world laced with GMCs is imagined, the picture still looks murky. Effects of mass cultivation of GMCs on ecology, agriculture, economy and health are many. These effects may compound every year with every new GMC. On analysing effects of any particular GMC in a particular geographical region, we anticipate many ecological, economic and ethical problems. Now, if we accumulate the effects of every single GMC growing in every corner of the world, the results may be disastrous. This in the backdrop of completely uncertain, unknown potential changes in climate could be even worse. Changing climatic conditions coupled with mass cultivation of GMCs could accentuate climate change impacts than mitigating them.

Moreover, abrupt, extreme and uncertain changes due to climate change require, agriculture model to be flexible and diverse so that it can easily adapt to changing situation. GMCs, grown as monoculture, are highly susceptible to complete crop failure in case of disease breakout or an environmental calamity like drought or flood. It also narrows the crop diversity and accentuates the danger of genetic pollution as well as extinction of many wild varieties even before they are discovered. It is an inflexible technology that requires years and millions of dollars for every new transgenic plant to be invented. Thus cultivation of these crops deteriorates the stability of the agricultural system and holds little hope for combating climate change.

\section{CONCLUSION}

The inherent power of GMCs, which can go a long way in serving mankind, is not doubtful. However, controversies over its health, economic, ecological and ethical implications, mar its role in serving mankind in any possible way. On the basis of above insight into both the 
Table 1. Countries growing GMCs and their respective Cartagena Protocol on Biosafety status.

\begin{tabular}{|c|c|c|}
\hline Country & GMCs grown & Cartagena Status \\
\hline Argentina $^{\#}$ & Soybean, Maize, Cotton & Not ratified \\
\hline Australia $^{\#}$ & Cotton, canola & Not ratified \\
\hline Bolivia $^{@}$ & Soybean & Ratified \\
\hline $\mathrm{Brazil}^{\$}$ & Soybean, Maize, Cotton & Accession \\
\hline Burkina Faso@ & Cotton & Ratified \\
\hline Canada $^{\#}$ & Canola, Maize, Soybean, Sugarbeet & Not ratified \\
\hline Chile $^{\#}$ & Maize, Soybean, Cotton & Not ratified \\
\hline China $^{@}$ & Cotton, Tomato, Poplar, Papaya, Sweet pepper & Ratified \\
\hline Colombia $^{@}$ & Cotton & Ratified \\
\hline Costa rica $^{@}$ & Cotton & Ratified \\
\hline Cuba $^{@}$ & Maize & Ratified \\
\hline Czech Republic ${ }^{@}$ & Maize & Ratified \\
\hline Egypt $^{@}$ & Maize & Ratified \\
\hline Germany $^{@}$ & Potato & Ratified \\
\hline Honduras@ & Maize & Ratified \\
\hline India $^{@}$ & Cotton & Ratified \\
\hline Mexico@ $^{@}$ & Cotton, Soybean & Ratified \\
\hline Myanmar ${ }^{@}$ & Cotton & Ratified \\
\hline Pakistan $^{@}$ & Cotton & Ratified \\
\hline Paraguay ${ }^{@}$ & Soybean & Ratified \\
\hline Philippines $^{@}$ & Maize & Ratified \\
\hline Poland $^{@}$ & Maize & Ratified \\
\hline Portugal $^{@}$ & Maize & Ratified \\
\hline Romania $^{@}$ & Maize & Ratified \\
\hline Slovakia@ & Maize & Ratified \\
\hline South Africa ${ }^{\$}$ & Maize, Soybean, Cotton & Accession \\
\hline Spain $^{@}$ & Maize & Ratified \\
\hline Sudan $^{@}$ & Cotton & Ratified \\
\hline Sweden ${ }^{@}$ & Potato & Ratified \\
\hline $\mathrm{USA}^{\#}$ & Canola, Maize, Soybean, Sugarbeet, Cotton, Squash, Papaya, Alfalfa & Not ratified \\
\hline Uruguay ${ }^{\#}$ & Soybean, Maize & Not ratified \\
\hline
\end{tabular}

Source: Clive, 2012 and List of parties, CBD. Notes: ${ }^{@}$-ratified (States which have signed a treaty, when it was open for signature, that can proceed to ratify it. Signature of itself does not establish consent to be bound, hence the further act of ratification.); ${ }^{\$}$-accession (States which have not signed a treaty during the time when it is open for signature can only accede to it. Therefore the term "accession"); "-not ratified.

contentious issues; Climate change and GMCs, it emerges that the occurrence and impacts of both are highly uncertain and unsettled. So, overlaying the doubtful aspects of GMCs on the uncertain, sudden potential impacts of Climate Change, paints an unsettling face for our future.

Based on the literature study, gaps in current knowledge in GMCs and its prospect as a solution to Climate Change are acknowledged. Lack of factual scientific data, absence of post commercial cultivation monitoring, misrepresented data, wrongful interpretation and modification of existing information, together generate massive asymmetrical knowledge base.

Providing food for all, remains at the heart of the entire problem. But research and development have lost focus from this important need and wandered in different directions. Providing food to all not only requires producing more but also maintaining, storing and transporting it hygienically with minimum wastage. According to Food Corporation of India, food worth Rs.500 billion (\$120 bn) is wasted every year. These post-harvest losses are about 25 - 30 percent of total agricultural produce [27]. Grain saved is grain produced. So the need is to save the existing food than producing more by altering genetic path and disturbing ecology.

Along with it, increasing the existing food production with minimal energy inputs like pesticides, fertilizers, from the existing land under agriculture is required. This is possible only if we change our input intensive form of cultivation to a sustainable one. Reducing pesticide, fertilizers and irrigation facilities to bare minimum and using 
alternatives like organic farming, will help in solving the problem of climate change to an extent as well as a befitting replacement to GMCs. Unless this is done, international efforts, like Conventions on Biodiversity and Climate Change, will continue being failures like the recently held COP16 at Cancun, Mexico. Such conventions are more of political and economic negotiating efforts with little result. Until economic concerns remain the main driving force behind such conventions, drawing any real, remarkable gains from them appears impossible.

Thus, we deduce from the above synthesis that the current approach to the issue of GMCs usage in agriculture and/or as a solution to CC, is still subject to scrutiny. It is economic driven and is based on illusory benefits. A fair, extensive and underpinning research is the need of the hour. Aim of this synthesis is to trigger thought process and research in the field of GMCs as a forbearer to climate change. We need to rethink our agricultural innovations and technologies, change our industrial approach to agriculture and collaborate with indigenous knowledge of locals to give it a new direction.

\section{ACKNOWLEDGEMENTS}

We express our gratitude to our institutions for allowing and encouraging us to work.

\section{REFERENCES}

[1] Nisbet, M.C., Hixon, M.A., Moore, K.D. and Nelson, M. (2010) Four cultures: New synergies for engaging society on climate change. Frontiers in Ecology and the Environment, 8, 329-331. http://dx.doi.org/10.1890/1540-9295-8.6.329

[2] Parry, M.L., Rosenzweig, C., Iglesias, A., Livermore, M. and Fischer, G. (2004) Effects of climate change on global food production under SRES emissions and socio economic scenarios. Global Environmental Change, 14, 53-67. http://dx.doi.org/10.1016/j.gloenvcha.2003.10.008

[3] Clive, J. (2012) Global status of commercialized biotech/ GM crops: 2012 [Internet]. ISAAA, Ithaca. http://www.isaaa.org/resources/publications/briefs/44

[4] Choudhary, B. and Gaur, K. (2010) Bt cotton in India: A country profile [Internet]. ISAAA, Ithaca.

http://www.isaaa.org/resources/publications/biotech crop _profiles/bt_cotton_in_india-a_country_profile/download /Bt_Cotton_in_India-A_Country_Profile.pdf

[5] MoA (2010) Department of agriculture and co-operation, annual report 2009-10. Ministry of Agriculture, Government of India Press, New Delhi.

[6] Heinemann, J.A. (2009) Hope not hype: The future of agriculture guided by the international assessment of agricultural knowledge, science and technology for development [Internet]. Third World Network, Penang. http://www.twnside.org.sg/title2/books/Hope.not.Hype.ht $\underline{\mathrm{m}}$

[7] Phipps, R.H. and Park, J.R. (2002) Environmental bene- fits of genetically modified crops: Global and European perspectives on their ability to reduce pesticide use. Journal of Animal and Feed Sciences, 11, 1-18.

[8] Qaim, M. and Zilberman, D. (2003) Yield effects of genetically modified crops in developing countries. Science, 299, 900-902. http://dx.doi.org/10.1126/science.1080609

[9] Wang, S., Just, D.R. and Anderson, P.P. (2008) Bt-cotton and secondary pests. International Journal of Biotechnology, 10, 113-114. http://dx.doi.org/10.1504/IJBT.2008.018348

[10] Nagrare, V.S., Kranthi, S., Biradar, V.K., Zade, N.N., Sangode, V., Kakde, G., Shukla, R.M., Shivare, D., Khadi, B.M. and Kranthi, K.R. (2009) Widespread infestation of the exotic mealybug species, Phenacoccus solenopsis (Tinsley) (Hemiptera: Pseudococcidae), on cotton in India. Bulletin of Entomological Research, 99, 537-541. http://dx.doi.org/10.1017/S0007485308006573

[11] Tabashnik, B.E. and Carrière, Y. (2010) Field-evolved resistance to bt cotton: Bollworm in the US and pink bollworm in India. Southwestern Entomologist, 35, 417-424. http://dx.doi.org/10.3958/059.035.0326

[12] Powles, S.B. (2008) Evolved glyphosate-resistant weeds around the world: lessons to be learnt. Pest management. Science, 64, 360-365.

[13] Sanvido, O., Stark, M., Romeis, J. and Bigler, F. (2006) Ecological impacts of genetically modified crops [Internet]. Agroscope Reckenholz-Tanikon Research Station ART, Zurich. http://www.agroscope.admin.ch/data/publikationen/ART_ SR_01_E.pdf

[14] Su, X.H., Zhang, B.Y., Huang, Q.J., Huang, L.J. and Zhang, X.H. (2003) Advances in tree genetic engineering in China. Paper Submitted to the XII World Forestry Congress. Quebec City.

[15] FOE (2010) Who benefits from gm crops? The great climate change swindle [Internet]. Sept 2010. Friends of the Earth International, Amsterdam.

http://www.foei.org.en/resources/publications/pdfs/2010/ who-benefits-from-gm-crops-2010

[16] Action Group on Erosion, Technology and Concentration (2010) Gene giants stockpile patents on climate ready crops in bid to become "Biomassters". Paper Presented at UN's Convention on Biodiversity, Nagoya.

[17] Godfrey, J. (2000) Do genetically modified goods affect human health? Lancet, 355, 414. http://dx.doi.org/10.1016/S0140-6736(05)74043-5

[18] Acosta, A. (2000) Transgenic foods: Promise or peril? Americas, 52, 14-15.

[19] Bakshi, A. (2003) Potential adverse health effects of genetically modified crops. Journal of Toxicology and Environmental Health, 6, 211-225. http://dx.doi.org/10.1080/10937400306469

[20] Pusztai, A. and Ewen, S.W. (1999) Effect of diets containing genetically modified potatoes expressing Galanthus nivalislectin on rat small intestine. Lancet, 354, 1353-1354. http://dx.doi.org/10.1016/S0140-6736(98)05860-7

[21] Ramdas, S.R. (2010) Bt cotton and livestock: Health 
impacts, bio-safety concerns and the legitimacy of public scientific research institutions. Paper Presented at National workshop on Genetically modified crops/foods \& Health Impacts. Centre for Sustainable Agriculture, Doctors for Food \& Bio-Safety, Greenpeace India and Sustainet. India International Centre, New Delhi.

[22] Smith, J. (2009) Genetic roulette: The documented health risks of Genetically Engineered foods. Yes! Books.

[23] Jayaraman, K. (2010) Bt brinjal splits Indian cabinet. Nature Biotechnology, 28, 296.

http://dx.doi.org/10.1038/nbt0410-296

[24] Raney, T. (2006) Economic impact of transgenic crops in developing countries. Current Opinions on Biotechnology, 17, 174-178.

http://dx.doi.org/10.1016/j.copbio.2006.02.009
[25] Gruere, G.P., Mehta-Bhatt, P. and Sengupta, D. (2008) Bt cotton and farmer suicides in India: Reviewing the evidence [Internet]. International Food Policy Research Instatute, Washington DC.

http://www.ifpri.org/sites/default/files/pubs/pubs/dp/ifprid p00808.pdf

[26] Convention on Biological Diversity (2000) List of parties [Internet]. 2011. Convention on Biological Diversity, Quebec.

http://www.cbd.int/convention/parties/list/

[27] Boxall, R.A. (2001) Post-harvest losses to insects: A world overview. International Biodeterioration \& Biodegradation, 48, 137-152.

http://dx.doi.org/10.1016/S0964-8305(01)00076-2 